\title{
When COVID-19 affects muscle: effects of quarantine in older adults
}

\author{
Tatiana Moro $(1,2)$, Antonio Paoli $(1,2)$ \\ (1) Department of Biomedical Sciences, University of Padova, Italy; (2) CIR-Myo, University of \\ Padova, Italy \\ This article is distributed under the terms of the Creative Commons Attribution Noncommercial License (CC BY-NC 4.0) which permits \\ any noncommercial use, distribution, and reproduction in any medium, provided the original author(s) and source are credited.
}

\begin{abstract}
At the beginning of 2020 a respiratory diseased named COVID-19 rapidly spread worldwide. Due to the presence of comorbidities and a greater susceptibility to infections, older adults are the population most affected by this pandemic. An efficient pharmacological treatment for COVID-19 is not ready yet; in the meanwhile, a general quarantine has been initiated as a preventive action against the spread of the disease. If on one side this countermeasure is slowing the spread of the virus, on the other side is also reducing the amount of physical activity. Sedentariness is associated with numerous negative health outcomes and increase risk of fall, fractures and disabilities in older adults. Models of physical inactivity have been widely studied in the past decades, and most studies agreed that is necessary to implement physical exercise (such as walking, low load resistance or in bed exercise) during periods of disuse to protect muscle mass and function from catabolic crisis. Moreover, older adults have a blunted response to physical rehabilitation, and a combination of intense resistance training and nutrition are necessary to overcome the loss of in skeletal muscle due to disuse.
\end{abstract}

Key Words: COVID-19, step reduction, aging, exercise

Eur J Transl Myol 30 (2):219-222, 2020

Coronavirus Disease 2019 (COVID-19) is a viral respiratory disease which is affecting millions of people worldwide. The presence of other comorbidities is one of the major risk factors for mortality from COVID- $19,{ }^{1}$ and for this reason case fatalities ratio is particularly high in older adult, ${ }^{2-4}$ with a prevalence in males compare to females in most countries. ${ }^{3}$ At this time, the effect of virus SARS-CoV2 on human organism are complex and, as a consequence, it does not exist a secure and mutually agreed treatment. It comes naturally that, in this emergency situation, prevention is the key intervention to adopt. For this reason, to prevent new infections a global lock down strategy has been adopted and people have been forced to stay in their home and avoid any type of social activity, ${ }^{5}$ including physical exercise and non-vital therapies. If on one side this approach is protecting those most at risk of infection, on the other side is implementing sedentary time. ${ }^{6}$ Sedentary lifestyle is associated with numerous negative health outcomes, such as cardiovascular disease, musculoskeletal disorders, cognitive decline, and an increase of overall mortality. ${ }^{7}$ Is worth to note that a short term (14 days) reduction of physical activity (i.e. from 10,000 to 1,500 steps/day) can impact insulin sensitivity and cardiorespiratory fitness, increase visceral fat and develop dyslipidemia in healthy young adults. ${ }^{8}$ Similar protocols of step reduction have even more evident effect on older adults. For example, a study conducted by Breen and coll. ${ }^{9}$ showed that 14 days of reduced step activity were sufficient to promote low grade inflammation, reduce insulin sensitivity by $\sim 43 \%$ and postprandial rates of protein synthesis (MPS) by $\sim 26 \%$ in healthy older adults. These translated into a $\sim 4 \%$ loss of leg lean mass, which is quite dramatic considering that, under physiological condition, older adults lose $\sim 0.8 \%$ of muscle mass per year. ${ }^{10}$ The rapid loss of muscle mass during periods of disuse is explained by a decrease in protein synthesis and increases in protein degradation rates. On a molecular point of view, inactivity seems to alter muscle metabolism primary reducing members of the Protein kinase B (Akt) signaling pathway. Akt is a central anabolic regulator with a dual function: enhances protein synthesis via mammalian target of rapamycin complex 1 (mTORC1) stimulation and inhibits protein degradation suppressing Forkhead box FOXO proteins action and their downstream. ${ }^{11}$ During inactivity the IGF1/Akt is inhibited and the activation of ubiquitindependent proteosome pathway, in particular muscle ring finger1 (MuRF1) and muscle atrophy F-box (MAFbx), are enhanced and promote muscle protein 


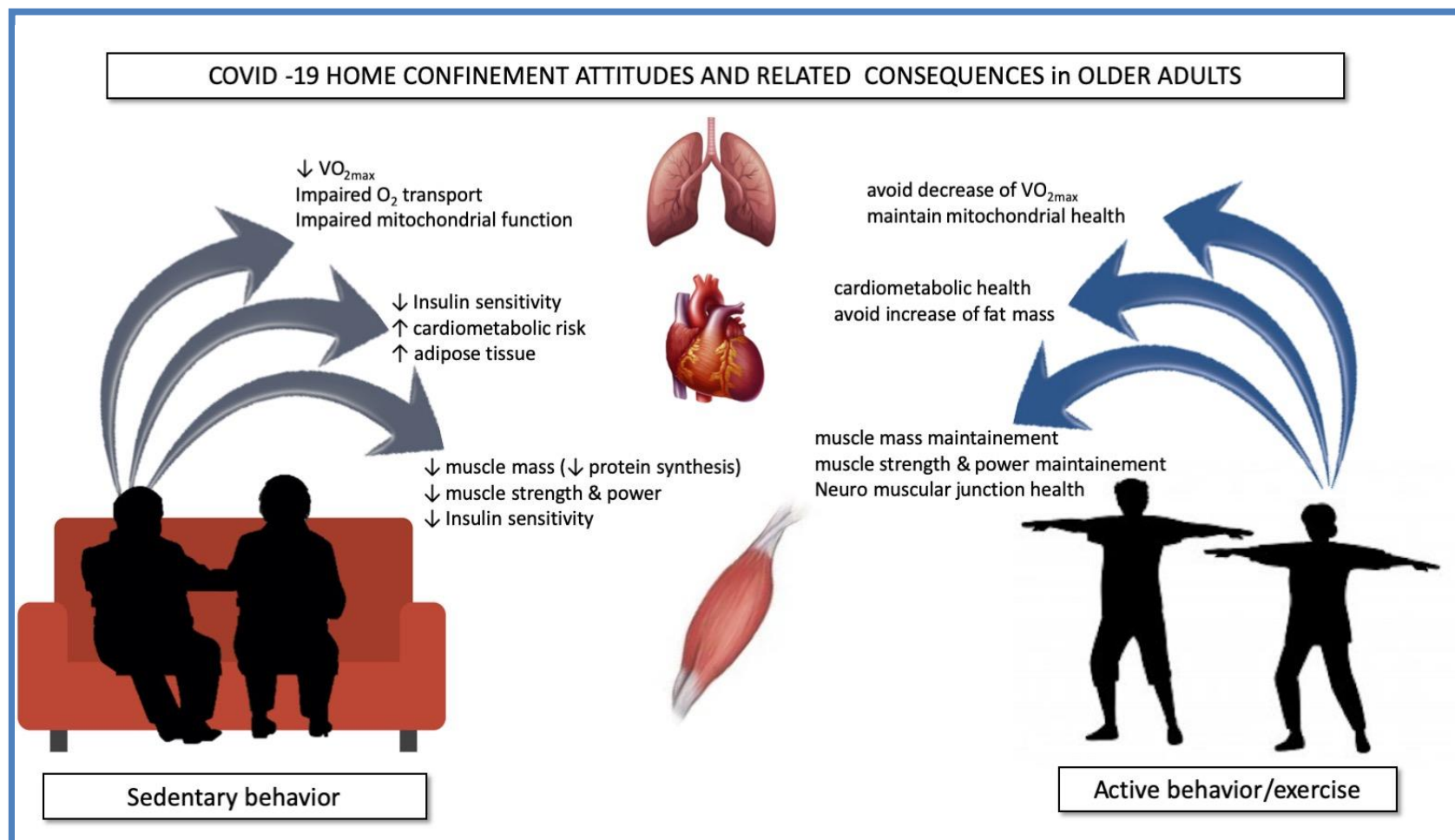

Fig 1. A schematic to summarize the effect of physical inactivity or activity on muscle mass, cardiovascular system and metabolism in older adults.

breakdown. ${ }^{12,13}$ Moreover, during disuse inflammatory cytokines may play a critical role in protein wasting. It has been indeed observed that in condition of muscle atrophy, TNF-a, a pro-inflammatory cytokine, activates the Nuclear factor kappa B-dependent (NF- $\mathrm{KB})$ pathway inducing protein degradation. ${ }^{14}$ As a consequence, older adults develops a resistance to any anabolic stimuli (exercise, nutrition) which promotes muscle atrophy. ${ }^{15}$ Recent studies has also indicate that muscle atrophy during period of disuse are accompanied by a reduction of satellite cells activity. ${ }^{16}$ Satellite cells (SCs) are essential source of new myonuclei and important contributor of muscle repair. Aging induce a decrease in SCs content probably due to endocrine changes as well as changes in the local SC environment, ${ }^{17}$ or an unappropriated proliferation of SCs. A decrease of this myogenic cells and their self-renewal capacity may contribute to the diminished anabolic response of older adults and can seriously impairs recovery and quality of life in older adults after periode of inactivity. In addition, as an effect of disuse, the ability to recruit motor unit is impaired resulting in a general reduction of intrinsic muscle force (force/cross sectional area) ${ }^{18}$ Short period of inactivity associated with changes in lifestyles as the one caused by COVID-19, may thus induce a "catabolic crisis" which can seriously increase risk of fall, fractures and disabilities (Figure 1). A recent study demonstrated that 2,000 steps/day was not enough to fully counteract the catabolic effects of bed rest in healthy older adults. ${ }^{19}$.
General guidelines recommend at least $150 \mathrm{~min}$ of moderate to vigorous physical activity per week to promote health and functional capacity, ${ }^{20}$ which are not feasible during the present lockdown. Performing moderate intensity exercise during periods of step reduction, such as walking for 45 minutes,${ }^{21}$ or low-load resistance training, ${ }^{22}$ prevents alteration of insulin sensitivity and protect from muscle and function loss. As an alternative, full-body in-bed gym, ${ }^{23}$ or home base FES exercise, ${ }^{24}$ help to preserve the independence of frail older people.

Ultimate guidelines on exercise protocols during period of reduced activity are not available yet, however studies from the literature seems to underline the importance of keep moving for conserving anabolic and insulin sensibility (Figure 1). The post-inactivity phase will also be a cause of concern for the elder population. It seems indeed that older adults are not able to properly recuperate muscle mass and strength after short-term period of disuse, ${ }^{25,26}$, even when more intense training protocols are employed. McGlory et al. showed that two weeks of habitual levels of physical activity were not sufficient to reestablish glucose metabolism nor to restore rates of MPS. ${ }^{27}$ Given that recovery from inactivity is measured and partial in older adults, it will be therefore necessary to implement post-COVID-19 exercise approach. To date, resistance exercise is the most efficient strategy to improve muscle mass and function in older adults, however 6 sessions spread in two 
weeks are not sufficient to fully recover muscle mass. ${ }^{25}$ Tanner et al demonstrated otherwise that older adults were able to reverse muscle mass and strength loss with 8 weeks of eccentric resistance exercise. ${ }^{28}$ Moreover, supplementation with high quality protein (such as 1.6 $\mathrm{g} / \mathrm{kg} /$ day of whey protein) in combination with physical exercise may help to stimulates MPS and improve muscle recovery in older adults. ${ }^{29}$

In conclusion, COVID-19 is constraining many people to a sedentary lifestyle. Older frail adults may be the ones more affected by this condition. It is imperative to keep exercising, even low load and sporadically bouts of exercise, during periods of inactivity. Once returned to the usual levels of physical activity, the combination of resistance exercise an nutritional stimuli (appropriate energy balance and high quality protein intake) seems to be the most effective strategy to counterbalance losses in skeletal muscle due to disuse.

\section{List of acronyms}

Akt - Protein kinase B

CoV2- Coronavirus 2

COVID-19 - Coronavirus disease 2019

FOXO - Forkhead box

IGF 1 - Insulin-like growth factor 1

MPS - muscle protein synthesis

mTORC1 - mammalian target of rapamycin complex 1

SARS - Severe Acute Respiratory Syndrome

MuRF1 - muscle ring finger1

MAFbx - muscle atrophy F-box

NF-кB - Nuclear factor kappa B-dependent

TNF-a - Tumor necrosis factor-a

\section{Authors contributions}

TM and AP fully wrote the article.

\section{Acknowledgments}

Funding

None

\section{Conflict of Interest None.}

\section{Ethical Publication Statement}

We confirm that we have read the Journal's position on issues involved in ethical publication and affirm that this report is consistent with those guidelines.

\section{Corresponding Author}

\section{Antonio Paoli,}

Department of Biomedical Sciences, University of Padova, Italy. Nutrition and Exercise Physiology Lab Via Marzolo, 3. 35131 Padova Italy

Phone: +390498275318, Fax: +390498275301.

ORCID iD: 0000-0003-0474-4229

Email: antonio.paoli@unipd.it

E-mail and ORCID iD of co-author

Tatiana Moro: tatiana.moro@unipd.it ORCID iD: 0000-0002-1404-1511

\section{References}

1. Wang B, Li R, Lu Z, Huang Y. Does comorbidity increase the risk of patients with COVID-19: evidence from meta-analysis. Aging (Albany NY) 2020;12:6049-57. e-pub ahead of print 2020/04/09.

2. Verity R, Okell LC, Dorigatti I, et al. Estimates of the severity of coronavirus disease 2019: a modelbased analysis. Lancet Infect Dis 2020. e-pub ahead of print 2020/04/03.

3. Shim E, Tariq A, Choi W, et al. Transmission potential and severity of COVID-19 in South Korea. Int J Infect Dis 2020;93:339-44. e-pub ahead of print 2020/03/22.

4. Le Couteur DG, Anderson RM, Newman AB. COVID-19 is a disease of older people. J Gerontol A Biol Sci Med Sci 2020. e-pub ahead of print 2020/03/31.

5. Carraro U. 2020PMD, 30-years of Translational Mobility Medicine at the time of COVID-19 outbreak: Last-minute forewords from the editor. Eur J Transl Myol. 2020;30(1):8966. doi.org/10.4081/ejtm.2019.8966

6. Narici M, De Vito G, Franchi M, et al. Impact of sedentarism due to the COVID-19 home confinement on neuromuscular, cardiovascular and metabolic health: Physiological and pathophysiological implications and recommendations for physical and nutritional countermeasures. Eur J Sport Sci 2020:1-22. doi: 10.1080/17461391.2020.1761076. [Epub ahead of print]

7. Leong DP, Teo KK, Rangarajan S, et al. Prospective Urban Rural Epidemiology Study i. Prognostic value of grip strength: findings from the Prospective Urban Rural Epidemiology (PURE) study. Lancet 2015; 386: 266-273. e-pub ahead of print 2015/05/20.

8. Bowden Davies KA, Sprung VS, et al. Short-term decreased physical activity with increased sedentary behaviour causes metabolic derangements and altered body composition: effects in individuals with and without a first-degree relative with type 2 diabetes. Diabetologia 2018;61:1282-94. e-pub ahead of print 2018/04/20.

9. Breen L, Stokes KA, Churchward-Venne TA, et al. Two weeks of reduced activity decreases leg lean mass and induces "anabolic resistance" of myofibrillar protein synthesis in healthy elderly. J Clin Endocrinol Metab 2013;98:2604-12. e-pub ahead of print 2013/04/17.

10. McLeod M, Breen L, Hamilton DL, Philp A. Live strong and prosper: the importance of skeletal muscle strength for healthy ageing. Biogerontology 2016; 7:497-510. e-pub ahead of print 2016/01/23.

11. Leger B, Cartoni R, Praz M, et al. Akt signalling through GSK-3beta, mTOR and Foxo1 is involved in human skeletal muscle hypertrophy and atrophy. 


\section{Effects of COVID-19 quarantine in muscles of older adults}

Eur J Transl Myol 30 (2) 219-222, 2020

J Physiol 2006;576:923-33. e-pub ahead of print 2006/08/19.

12. Suetta C, Frandsen U, Jensen L, et al. Aging affects the transcriptional regulation of human skeletal muscle disuse atrophy. PLoS One 2012;7:e51238. e-pub ahead of print 2013/01/04.

13. Dirks ML, Wall BT, Nilwik R, et al. Skeletal muscle disuse atrophy is not attenuated by dietary protein supplementation in healthy older men. J Nutr 2014; 144: 1196-1203. e-pub ahead of print 2014/06/13.

14. Guttridge DC, Mayo MW, Madrid LV, et al. NFkappaB-induced loss of MyoD messenger RNA: possible role in muscle decay and cachexia. Science 2000;289:2363-6. e-pub ahead of print 2000/09/29.

15. Drummond MJ, Dickinson JM, Fry CS, et al. Bed rest impairs skeletal muscle amino acid transporter expression, mTORC1 signaling, and protein synthesis in response to essential amino acids in older adults. Am J Physiol Endocrinol Metab 2012;302:E1113-22. e-pub ahead of print 2012/02/14

16. McKenna CF, Fry CS. Altered satellite cell dynamics accompany skeletal muscle atrophy during chronic illness, disuse, and aging. Curr Opin Clin Nutr Metab Care 2017;20:447-452. doi:10.1097/MCO.0000000000000409

17. Garg K, Boppart MD. Influence of exercise and aging on extracellular matrix composition in the skeletal muscle stem cell niche. J Appl Physiol (1985). 2016;121(5):1053-8. Epub 2016/08/18. doi: 10.1152/japplphysiol.00594.2016. PubMed PMID: 27539500; PubMed Central PMCID: PMCPMC5142247

18. Narici MV, de Boer MD. Disuse of the musculoskeletal system in space and on earth. Eur J Appl Physiol 2011;111:403-20. e-pub ahead of print 2010/07/10.

19. Arentson-Lantz E, Galvan E, Wacher A, et al. 2,000 Steps/Day Does Not Fully Protect Skeletal Muscle Health in Older Adults During Bed Rest. J Aging Phys Act 2019;27:191-197. e-pub ahead of print 2018/07/11.

20. American College of Sports M, Chodzko-Zajko WJ, Proctor DNet al. American College of Sports Medicine position stand. Exercise and physical activity for older adults. Med Sci Sports Exerc 2009;41:1510-30. e-pub ahead of print 2009/06/12.

21. Walhin JP, Richardson JD, Betts JA, Thompson D. Exercise counteracts the effects of short-term overfeeding and reduced physical activity independent of energy imbalance in healthy young men. J Physiol 2013;591:6231-43. e-pub ahead of print 2013/10/30.

22. Devries MC, Breen L, Von Allmen M, et al. Lowload resistance training during step-reduction attenuates declines in muscle mass and strength and enhances anabolic sensitivity in older men. Physiol Rep 2015;3. e-pub ahead of print 2015/08/13.

23. Carraro U, Gava K, Baba A, et al. To Contrast and Reverse Skeletal Muscle Atrophy by Full-Body InBed Gym, a Mandatory Lifestyle for Older Olds and Borderline Mobility-Impaired Persons. Adv Exp Med Biol 2018;1088:549-60. e-pub ahead of print 2018/11/06.

24. Taylor MJ, Schils S, Ruys AJ. Home FES: An Exploratory Review. Eur J Transl Myol. 2019 Nov 12;29(4):8285. doi: 10.4081/ejtm.2019.8285. eCollection 2019 Oct 29. PMID: 31969976 Free PMC article.

25. Rejc E, Floreani M, Taboga P, et al. Loss of maximal explosive power of lower limbs after 2 weeks of disuse and incomplete recovery after retraining in older adults. J Physiol 2018;596:64765. e-pub ahead of print 2017/12/22.

26. Hvid L, Aagaard P, Justesen L, et al. Effects of aging on muscle mechanical function and muscle fiber morphology during short-term immobilization and subsequent retraining. J Appl Physiol (1985) 2010;109:1628-34. e-pub ahead of print 2010/09/25.

27. McGlory C, von Allmen MT, Stokes T, et al. Failed Recovery of Glycemic Control and Myofibrillar Protein Synthesis With 2 wk of Physical Inactivity in Overweight, Prediabetic Older Adults. J Gerontol A Biol Sci Med Sci 2018;73:1070-7. e-pub ahead of print 2017/11/03.

28. Tanner RE, Brunker LB, Agergaard J, et al. Agerelated differences in lean mass, protein synthesis and skeletal muscle markers of proteolysis after bed rest and exercise rehabilitation. $\mathrm{J}$ Physiol 2015;593:4259-73. e-pub ahead of print 2015/07/15

29. Oikawa SY, McGlory C, D'Souza LK, et al. A randomized controlled trial of the impact of protein supplementation on leg lean mass and integrated muscle protein synthesis during inactivity and energy restriction in older persons. Am J Clin Nutr 2018;108:1060-8. e-pub ahead of print 2018/10/06.

Submitted: April 30, 2020 Accepted for publication: May 162019 